\title{
Human erythropoietin increases the pro-angiogenic potential of A2780 ovarian adenocarcinoma cells under hypoxic conditions
}

\author{
JÁN KRIŠKA ${ }^{1}$, PETER SOLÁR ${ }^{1}$, LENKA VARINSKÁ ${ }^{2}$, ZUZANA SOLÁROVÁ $^{3}$, PATRÍCIA KIMÁKOVÁ ${ }^{1}$, \\ JÁN MOJŽIŠ ${ }^{2}$, PETER FEDOROČKO ${ }^{1}$ and ARTHUR J. SYTKOWSKI ${ }^{4,5}$ \\ ${ }^{1}$ Institute of Biology and Ecology, Faculty of Science, ${ }^{2}$ Department of Pharmacology, and ${ }^{3}$ Geriatric Nursing Clinic, \\ Faculty of Medicine, P.J. Šafárik University, Košice, Slovak Republic; ${ }^{4}$ Oncology Therapeutic Area, Therapeutic \\ Delivery Unit, Quintiles Transnational, Rockville, MD; ${ }^{5}$ Laboratory for Cell and Molecular Biology, Beth Israel \\ Deaconess Medical Center, Department of Medicine, Harvard Medical School, Boston, MA, USA
}

Received February 26, 2013; Accepted May 9, 2013

DOI: 10.3892/or.2013.2566

\begin{abstract}
Erythropoietin (Epo) is a key regulator of erythroid cell proliferation, differentiation and apoptosis. In the form of the recombinant protein, it is widely used to treat various types of anemias, including that associated with cancer and with the myelosuppressive effects of chemotherapy, particularly platinum-based regimens. Our previous studies confirmed the presence of Epo receptors (EpoRs) in ovarian adenocarcinoma cell lines and demonstrated that long-term Epo treatment of A2780 cells resulted in the development of a phenotype exhibiting both enhanced Epo signaling and increased paclitaxel resistance. In the present study, we carried out a series of experiments to analyze the pro-angiogenic potential of Epo-treated A2780 and SKOV-3 cells. Our studies revealed that conditioned media of Epo-treated A2780 cells had a stimulative effect on human umbilical vein endothelial cells (HUVECs). This effect was only seen when A2780 cells were incubated under hypoxic conditions. Furthermore, Epo increased the secretion of interleukin (IL)-4, IL-5, IL-6, IL-8, IL-10, IL-12, IL-13, GM-CSF and interferon- $\gamma$ by A2780 cells that grew in hypoxic conditions. In this regard, conditioned media of hypoxic and Epo-treated A2780 cells induced a significant phosphorylation of STAT-5 in HUVECs. Our results may have important implications for ovarian cancer patients receiving Epo.
\end{abstract}

\section{Introduction}

Erythropoietin (Epo) is a glycoprotein that regulates the growth, maturation, and survival of erythroid progenitor cells. Epo has received attention for its role(s) outside of hemato-

Correspondence to: Dr Peter Solár, Institute of Biology and Ecology, Faculty of Science, P.J. Šafárik University, 04001 Košice, Slovak Republic

E-mail: peter.solar@upjs.sk

Key words: erythropoietin, ovarian adenocarcinoma, A2780, angiogenesis, human umbilical vein endothelial cell poiesis (1). Several groups have demonstrated the presence of the Epo receptor (EpoR) expressed by ovarian cancer cells (2-5) with differing results regarding its localization and functionality. Our previous studies revealed a weak surface EpoR signal in A2780 cells with most of EpoR found in the cytoplasm, more abundantly as an intracellular membraneassociated protein than a soluble one. Silencing EpoR expression resulted in reduced A2780 proliferation as well as a reduction in Epo-induced phosphorylation of Erk1/2 (6). The presence and the functionality of EpoR have been confirmed in several other cancer cells. Unlike hematopoietic cells, where Epo/EpoR signaling is associated with increased cell proliferation and/or survival, in tumor cells the Epo/EpoR axis does not always lead to increased proliferation but may increase the resistance of cancer cells to different therapies. Szenajch et al (7) provide a critical review of this.

In 1990, Anagnostou et al (8) found that recombinant human Epo (rhEpo) enhances the proliferation and migration of human umbilical vein endothelial cells (HUVECs) and bovine adrenal capillary endothelial cells $(9,10)$ and demonstrated the presence of EpoR mRNA in HUVECs as well as strong positive EpoR protein staining of the vascular endothelium in vivo (11). The presence of EpoR was also shown by Yamaji et al (12), who suggested that brain capillary endothelial cells express not only an authentic form of EpoR but also a soluble one and that Epo acts directly on brain capillary endothelial cells as a competence factor. In vivo angiogenic potential of Epo was originally demonstrated by Yasuda et al (13) who found that injection of Epo into the ovariectomized mouse uterine cavity promoted blood vessel formation of the endometrium. Similarly, Ribatti et al (14) demonstrated that Epo induced a potent in vivo angiogenic response of the chick embryo chorioallantoic membrane. Furthermore, the role of Epo in the physiological angiogenesis was described during wound healing and in the developing of mouse embryo $(15,16)$.

The study of Yasuda et al (17) revealed that normal human cervix, endometrium as well as ovary malignant tumors of female reproductive organs produce Epo and EpoR, and that the tumor cells themselves and capillary endothelial cells are sites responsive to the Epo signal. Based on the mitogenic action of Epo as well as the finding that injection of soluble 
EpoR or Epo-monoclonal antibody into the tumor was followed by apoptosis of tumor cells, Yasuda et al (18) proposed the presence of a paracrine or autocrine Epo/EpoR loop and its contribution to tumorigenesis in female reproductive organs. Subsequently, Epo-induced angiogenesis was demonstrated on chemically induced murine hepatic tumors (19), glioma tumor cells in chick embryo chorioallantoic membrane (20) and melanoma cells in Matrigel plug assay (21). Epo also accelerated the growth of EpoR negative Lewis lung carcinoma cells by promoting tumor angiogenesis in vivo (22). Notably, Epo/ EpoR levels correlated well with angiogenesis and progression of patients with hepatocellular carcinoma, neuroblastoma, squamous cell carcinoma of the tongue, melanoma and gastric adenocarcinoma (23-27).

Although studies have not confirmed a direct stimulatory effect of rhEpo on tumor cells, there is ample evidence of this effect on endothelial cell proliferation and/or angiogenesis of tumors. We have now carried out a series of experiments to explore mechanisms of such an endothelial cell stimulation induced by conditioned media of diverse ovarian adenocarcinoma cells A2780 and SKOV-3. Both cell lines were incubated either in normoxic or hypoxic conditions and their conditioned media were investigated in order to test the proliferation of HUVECs. The potential pro-angiogenic effect of rhEpo, which remains in the conditioned media of rhEpo-treated A2780 and SKOV-3 cells, was also studied.

\section{Materials and methods}

Cell culture conditions. Human ovarian adenocarcinoma cell lines A2780 and SKOV-3 were obtained from the American Tissue Culture Collection. Both cell lines were grown in RPMI-1640 with L-glutamine (Life Technologies, Carlsbad, CA, USA). Media was supplemented with $10 \%$ FCS (Life Technologies) and antibiotic/antimycotic solution (100 U/ml penicillin, $100 \mu \mathrm{g} / \mathrm{ml}$ streptomycin, and $0.25 \mu \mathrm{g} / \mathrm{ml}$ amphotericin B; Life Technologies). The cells were maintained under standard tissue culture conditions of $37^{\circ} \mathrm{C}, 95 \%$ air $/ 5 \% \mathrm{CO}_{2}$.

HUVECs were isolated, cultured, and characterized as previously described $(28,29)$. Cells were cultured on gelatin-coated dishes in M199 media supplemented with $10 \%$ heat-inactivated human serum (PAA, Piscataway, NJ, USA), $10 \%$ heat-inactivated new born calf serum (Cambrex, East Rutherford, NJ, USA), $150 \mu \mathrm{g} / \mathrm{ml}$ crude endothelial cell growth factor (ECGF), $5 \mathrm{U} / \mathrm{ml}$ heparin, $100 \mathrm{IU} / \mathrm{ml}$ penicillin, and $100 \mu \mathrm{g} / \mathrm{ml}$ streptomycin (Sigma-Aldrich, St. Louis, MO, USA) at $37^{\circ} \mathrm{C}$ under a $5 \% \mathrm{CO}_{2} / 95 \%$ air atmosphere. Twenty-four hours prior to the experiments, the endothelial cell cultures were refreshed with a media without crude ECGF and heparin.

Cell culture treatments. A2780 and SKOV-3 cells were seeded at a density of $1 \times 10^{6}$ cells/Petri dish in RPMI-1640 media with $10 \%$ FCS for $24 \mathrm{~h}$. Subsequently, cells were washed with PBS and serum-free media with or without $50 \mathrm{U} / \mathrm{ml}$ of rhEpo (Eprex ${ }^{\circledR}$; Janssen-Cilag, Beerse, Belgium) was added. Half of the experimental Petri dishes were then moved to a hypoxic chamber with $1 \% \mathrm{O}_{2}$ and the other half were kept under standard tissue culture conditions, both for $24 \mathrm{~h}$. Conditioned media were then immediately added to HUVECs for 48 -h cell proliferation assay.
HUVEC proliferation assay. Endothelial cells were seeded at a density of $8 \times 10^{3}$ cells $/ \mathrm{cm}^{2}$ in 24 -well plates. Twenty-four hours after seeding, the conditioned media obtained from A2780 and SKOV-3 cells were added to endothelial cells in triplicate wells. Vascular endothelial growth factor (VEGF)-treated cells (R\&D Systems, Minneapolis, MN, USA) $(25 \mathrm{ng} / \mathrm{ml})$ were used as a positive control. After $48 \mathrm{~h}$ of culturing, the proliferation activity was determined using Coulter Counter (Model ZF; Coulter Electronics Ltd., Luton, Bedfordshire, UK) and the total viability was analyzed by staining cells with $0.15 \%$ eosine via light microscopy. Cell pellets, after being washed extensively with PBS, were dispersed in antifade mounting fluid, placed on glass slides SuperFrost Plus (Menzel Gläser, Braunschweig, Germany) and used for light microscopy using a Leica DMI6000 microscope at x400 magnification.

RNA isolation, reverse transcription and quantitative RT-PCR. Total RNA was isolated using TRIzol (Gibco, Invitrogen, Grand Island, NY, USA) and purified using RNeasy Mini kit (Qiagen, Hamburg, Germany). The RNA concentration was quantified at $260 \mathrm{~nm}$ and $1 \mu \mathrm{g}$ of RNA was transcribed using SuperScript II (Invitrogen, Carlsbad, CA, USA) reverse transcriptase and oligo(dT) primers (Invitrogen). Quantitative RT-PCRs were performed in duplicates by $\mathrm{iCycler}_{\mathrm{iQ}}^{\mathrm{TM}}$ Real-Time PCR Detection System (Bio-Rad Laboratories, Inc., Hercules, CA, USA) in $30 \mu 1$ reaction volume containing $1 \mathrm{X}$ $\mathrm{iQ}^{\mathrm{TM}}$ SYBR Green Supermix (0.2 mM dNTP, $3 \mathrm{mM} \mathrm{MgCl}$ ), $0.5 \mu \mathrm{M}$ forward and reverse primer and $2 \mu \mathrm{l}$ of cDNA. The reaction conditions were: $95^{\circ} \mathrm{C} 3 \mathrm{~min}, 40$ cycles $\left(94^{\circ} \mathrm{C} 30 \mathrm{sec}\right.$, $\left.55^{\circ} \mathrm{C} 50 \mathrm{sec}, 72^{\circ} \mathrm{C} 50 \mathrm{sec}\right), 72^{\circ} \mathrm{C} 7 \mathrm{~min}$ followed by melting curve analysis to confirm amplification of the desired single and specific product. The relative expression levels of hypoxiainducible factor-1 $\alpha$ (HIF-1 $\alpha)$, Epo, VEGF and $\beta$-actin genes (primers designed by SABiosciences) were evaluated using the standard curve method. Standard curves for HIF-1 $\alpha$, Epo, VEGF and $\beta$-actin were obtained by amplification of seriallydiluted mixtures of cDNA samples (four-fold dilutions), with four to five dilution points, each in duplicate. The calculated resulting relative expression of HIF-1 $\alpha$, Epo, VEGF genes were normalized to relative $\beta$-actin expression. The results are presented as mean \pm standard deviation of three independent experiments.

Western blot analysis. Western blot analyses were performed according to the standard protocol. HUVECs were incubated with conditioned media of A2780 cells for $30 \mathrm{~min}$. Then, the cells were washed twice with ice-cold PBS and scraped into RIPA buffer (PBS, 1\% Nonidet P-40, 0.5\% sodium deoxycholate, $0.1 \%$ SDS; all Sigma) containing freshly added protease and phosphatase inhibitor cocktail (Roche Diagnostics $\mathrm{GmbH}$, Penzberg, Germany). Scraped lysates were transferred into a microcentrifuge tube and passed through a 21-gauge needle to shear the DNA. Following incubation of the lysates on ice for $45 \mathrm{~min}$, the samples were centrifuged at $10,000 \mathrm{x} \mathrm{g}$ for $10 \mathrm{~min}$ at $4^{\circ} \mathrm{C}$ and the supernatant was transferred into a new microcentrifuge tube. The protein samples were separated on $10 \%$ SDS-PAGE gels, electroblotted onto Immobilon-P transfer membrane (Millipore Co., Billerica, MA, USA) and incubated using the following primary antibodies: 
anti-STAT5 (AF2168, 1:200; R\&D Systems), anti-phosphoSTAT5 (Y694/Y699) (AF4190, 1:100; R\&D Systems), anti p44/42 MAP kinase (\#9102, 1:1,000; Cell Signaling Technology, Danvers, MA, USA), anti-phospho-p44/42 MAP kinase (\#9272, 1:1,000; Cell Signaling Technology) and anti- $\beta$-actin (clone AC-74, 1:10,000; Sigma). The membranes were then incubated with secondary horseradish peroxidaseconjugated antibodies [goat anti-rabbit immunoglobulin $\mathrm{G}$ (IgG) F(AB9) 2, 1:10,000, PI-31461, goat anti-mouse IgG F(AB9) 2, 1:10,000, PI-31436 or rabbit anti-goat IgG F(AB9) 2, 1:10,000, PI-31403; Pierce, Rockford, IL, USA] for $1 \mathrm{~h}$, and the antibody reactivity was visualized with ECL western blotting substrate (PI-32106; Pierce) using Kodak BioMax film (\#1788207; Sigma).

ELISA assay. ELISA assay with Epo and VEGF detection was performed according to the manufacturer's instructions (R\&D Systems). Briefly, 96-well plates with diluent, standards, positive control and experimental samples were incubated for $2 \mathrm{~h}$ at room temperature and then each well was washed three times with washing solution. After the addition of VEGF or Epo conjugate, the plates were incubated for another $2 \mathrm{~h}$ at room temperature. Subsequently, substrates were added after repeated washing and plates were incubated protected from light for a further $20 \mathrm{~min}$. The enzymatic reaction was stopped by addition of stop solution and absorbance was measured at $\lambda=450 \mathrm{~nm}$ using a FLUOStar Optima universal microplate reader (BMG Labtech, Inc., Offenburg, Germany). The concentrations of Epo and VEGF in conditioned media were calculated based on standard curves.

Multi-analyte ELISA assay. The Mix-N-Match Multi-Analyte ELISArray kit (Qiagen) was identical to the common ELISA assay in protocol and development or incubation time. We used this assay to profile the levels of the following 12 cytokines: IL-2, IL-4, IL-5, IL-6, IL-8, IL-10, IL-12, IL-13, GM-CSF, interferon- $\gamma$ (IFN- $\gamma)$, tumor necrosis factor- $\alpha$ (TNF- $\alpha$ ) and transforming growth factor- $\beta 1$ (TGF- $\beta 1$ ).

Statistical analysis. Data were processed using scientific graphing and Origin analysis software (OriginLab Co., Northampton, MA, USA) and statistically analyzed using one-way ANOVA followed by Tukey's multiple comparison tests.

\section{Results}

We observed the effect of conditioned media of untreated as well as rhEpo-treated A2780 and SKOV-3 cells mainly due to changes in gene expression of HIF-1 $\alpha$, Epo and VEGF as well as in connection with the change of VEGF $_{165}$ secretion in both A2780 and SKOV-3 cell lines. Markedly, we found that the expression of HIF-1 $\alpha$ did not increase in A2780 cells after $24 \mathrm{~h}$ of incubation in hypoxia and, in the case of SKOV-3 cells, the expression of HIF-1 $\alpha$ even significantly decreased (probably by the mechanism of feedback regulation). Both A2780 and SKOV-3 cells showed $>95 \%$ viability after hypoxia incubation (data not shown). The administration of rhEpo, however, had no effect on the expression of HIF-1 $\alpha$ in both cell lines in either normoxic or hypoxic conditions (Fig. 1).

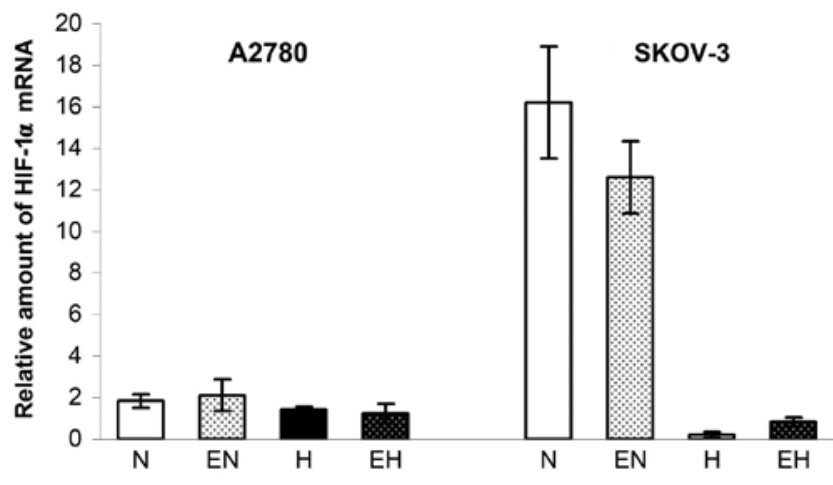

Figure 1. Exogenous erythropoietin (Epo) does not change the expression of hypoxia-inducible factor- $1 \alpha$ (HIF-1 $\alpha$ ) in A2780 and SKOV-3 cells. Relative amounts of HIF-1 $\alpha$ mRNA in A2780 and SKOV-3 cells incubated under normoxic $(\mathrm{N})$ or hypoxic $(\mathrm{H})$ conditions with or without $50 \mathrm{U} / \mathrm{ml}$ of recombinant Epo (E) for $24 \mathrm{~h}$. The expression of HIF-1 $\alpha$ gene was normalized to $\beta$-actin expression (HIF-1 $\alpha / \beta$-actin) and is shown as relative amount. Data are presented as means \pm SD of three independent experiments.

We analyzed the expression of the Epo gene and measured the amount of secreted endogenous Epo in conditioned media of A2780 and SKOV-3 cells under normoxic as well as hypoxic conditions. The expression of Epo was monitored by real-time PCR and clearly showed the presence of low concentrations of mRNA for Epo in both cell lines. The Epo expression was higher in A2780 compared to SKOV-3 cells (Fig. 2A). Furthermore, hypoxic conditions did not result in any stimulatory effect on the expression of Epo in A2780 and SKOV-3 cells. In addition, ELISA test results clearly showed low production of a secreted form of Epo protein under normoxia in both A2780 as well as SKOV-3 cells (Fig. 2B). Although the Epo gene expression remained unchanged in both cell lines under conditions of hypoxia (Fig. 2A), the concentration of secreted Epo protein increased from 5.3 to $38.9 \mathrm{mU} / \mathrm{ml}$ in conditioned media of hypoxic A2780 cells compared to normoxic ones. On the other hand, the concentration of secreted Epo in the conditioned media of SKOV-3 cells did not change under hypoxic conditions compared with normoxic ones (Fig. 2B). With regard to the application of rhEpo, we did not find any significant effect of $50 \mathrm{U} / \mathrm{ml}$ of rhEpo on the expression of Epo gene in A2780 and SKOV-3 cells (Fig. 2A).

In contrast to Epo and HIF-1 $\alpha$, the expression of VEGF was upregulated through the hypoxic conditions in both A2780 as well as SKOV-3 cells (Fig. 3A) without additional upregulation using rhEpo. The only change in VEGF expression after administration of rhEpo occurred when A2780 cells were incubated with a higher dose of rhEpo under normoxic conditions. Indeed, $150 \mathrm{U} / \mathrm{ml}$ enhanced the expression of VEGF in A2780 under normoxia, which was accompanied paradoxically by a decrease in $\mathrm{VEGF}_{165}$ secretion. Based on the application of anti-Epo antibody or soluble EpoR and observing even stronger decline of $\mathrm{VEGF}_{165}$ secretion, we hypothesized that it was a non-specific effect of such a high concentration of rhEpo (data not shown). However, enhanced mRNA level of VEGF under the hypoxia correlated well with higher secretion of $\mathrm{VEGF}_{165}$ in the SKOV-3 cell line only (Fig. 3B). On the other hand, rhEpo upregulated VEGF secretion in SKOV-3 cells under normoxic conditions without altering the gene expression for VEGF (Fig. 3). 

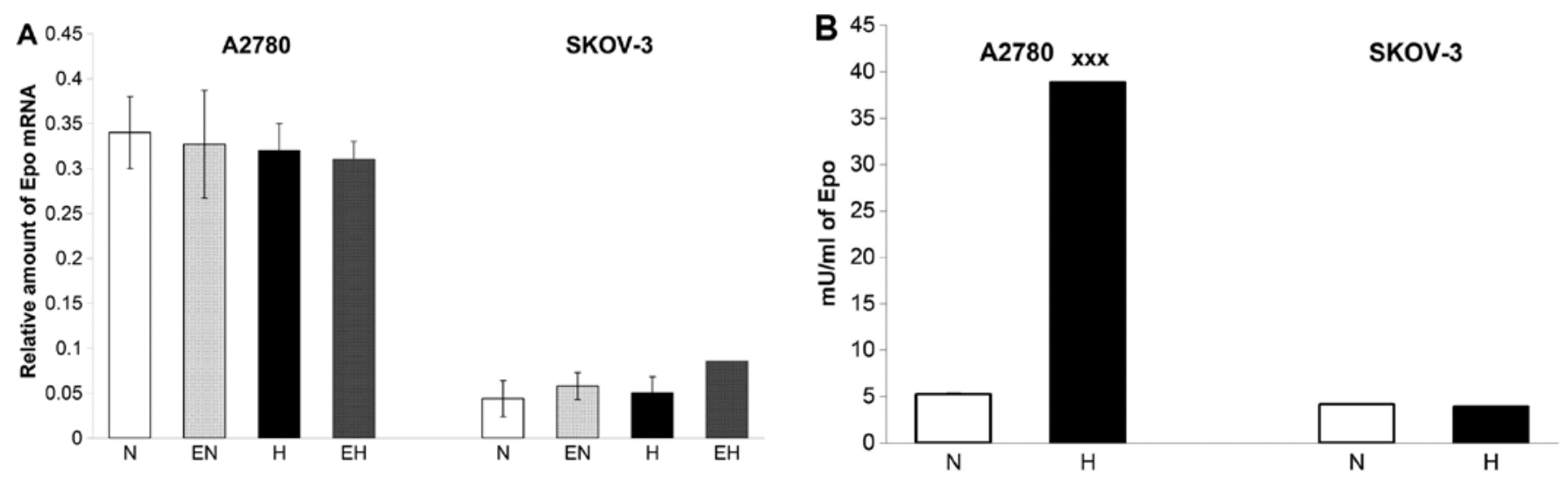

Figure 2. (A) Exogenous erythropoietin (Epo) does not change the expression of Epo in A2780 and SKOV-3 cells. Relative amounts of Epo mRNA in A2780 and SKOV-3 cells incubated under normoxic $(\mathrm{N})$ or hypoxic $(\mathrm{H})$ conditions with or without $50 \mathrm{U} / \mathrm{ml}$ of recombinant Epo (E) for $24 \mathrm{~h}$. The expression of Epo gene was normalized to $\beta$-actin expression (Epo/ $\beta$-actin) and is shown as relative amount. Data are presented as means $\pm \mathrm{SD}$ of three independent experiments. (B) Hypoxia stimulates Epo secretion of A2780 cells. A2780 and SKOV-3 cells were incubated in serum-free media under normoxic $(\mathrm{N})$ or hypoxic $(\mathrm{H})$ conditions for $24 \mathrm{~h}$. The concentrations of Epo in conditioned media were calculated based on standard curve and are expressed in $\mathrm{mU} / \mathrm{ml}$. Data are presented as means \pm SD of three independent experiments. The statistical significance is designated as follows: $\mathrm{H}$ vs. $\mathrm{N},{ }^{\mathrm{xxx}} \mathrm{P}<0.001$.
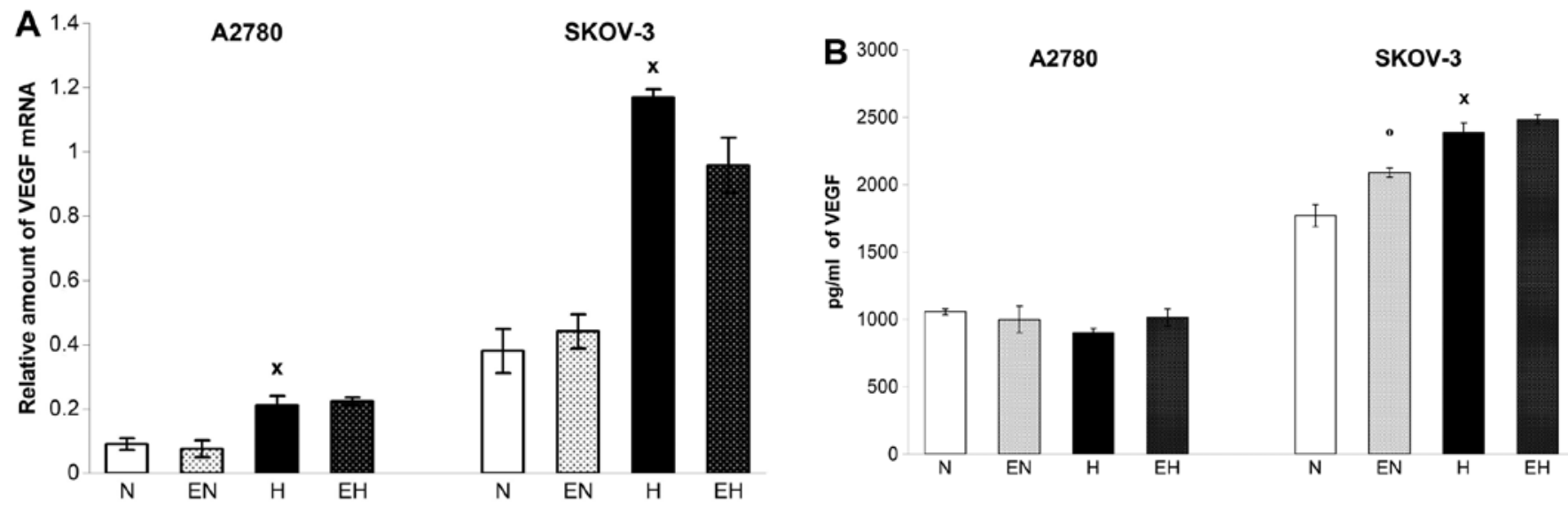

Figure 3. (A) Hypoxia but not exogenous erythropoietin (Epo) induces expression of vascular endothelial growth factor (VEGF) in A2780 and SKOV-3 cells Relative amounts of VEGF mRNA in A2780 and SKOV-3 cells treated with or without $50 \mathrm{U} / \mathrm{ml}$ of recombinant Epo (E) under normoxic (N) or hypoxic (H) conditions for $24 \mathrm{~h}$. The expression of VEGF gene was normalized to $\beta$-actin expression (VEGF/ $\beta$-actin) and is shown as relative amount. Data are presented as means $\pm \mathrm{SD}$ of three independent experiments. The statistical significance is designated as follows: $\mathrm{H} v \mathrm{vs} . \mathrm{N} \times \mathrm{P}<0.05$. (B) Exogenous Epo stimulates VEGF secretion of SKOV-3 cells under normoxic conditions. A2780 and SKOV-3 cells were treated with or without $50 \mathrm{U} / \mathrm{ml}$ of recombinant Epo under N or H conditions for $24 \mathrm{~h}$. The concentrations of VEGF in conditioned media were calculated based on standard curve and are expressed in $\mathrm{pg} / \mathrm{ml}$. Data are presented as means $\pm \mathrm{SD}$ of three independent experiments. The statistical significance is designated as follows: $\mathrm{EN}$ vs. $\mathrm{N},{ }^{\circ} \mathrm{P}<0.05 ; \mathrm{H}$ vs. N, ${ }^{\times} \mathrm{P}<0.05$.

The pro-angiogenic potential of conditioned media from A2780 and SKOV-3 cells was monitored by HUVEC proliferation. All conditioned media, including those originating from A2780 and SKOV-3 cells incubated with $50 \mathrm{U} / \mathrm{ml}$ of rhEpo as well as control with rhVEGF and rhEpo were added to HUVECs for $48 \mathrm{~h}$. The result of stimulation and/or proliferation was evaluated by simple counting of HUVECs using the Coulter Counter. In this regard, conditioned media of A2780 and SKOV-3 cells kept under normoxic conditions had no significant effect on the proliferation of HUVECs compared with rhVEGF control (Fig. 4A). The opposite was observed when HUVECs were incubated with conditioned media of hypoxic A2780 and SKOV-3 cells. These media significantly increased the proliferation of HUVECs compared with rhVEGF control and compared with conditioned media of A2780 and SKOV-3 cells incubated under normoxic condi- tions (Fig. 4A). A marked finding was that conditioned media collected from A2780 cells incubated under hypoxic conditions with $50 \mathrm{U} / \mathrm{ml}$ of rhEpo had a more pronounced stimulatory effect on HUVECs than the media of hypoxic A2780 cells without rhEpo. Paradoxically, conditioned media of SKOV-3 cells incubated under hypoxic conditions with the same concentration of rhEpo inhibited the proliferation of HUVECs compared to media of hypoxic SKOV-3 cells without rhEpo (Fig. 4). In order to establish the actual proportion of Epo to stimulate HUVECs, we used neutralizing anti-Epo monoclonal antibody. The stimulation of HUVECs by conditioned media of hypoxic A2780 cells as well as by hypoxic media of rhEpo-treated A2780 cells was blocked using anti-Epo antibody. Contrary to A2780, we did not observe the same blocking effect of anti-Epo antibody in the case of conditioned media of SKOV-3 cells incubated under hypoxic conditions 


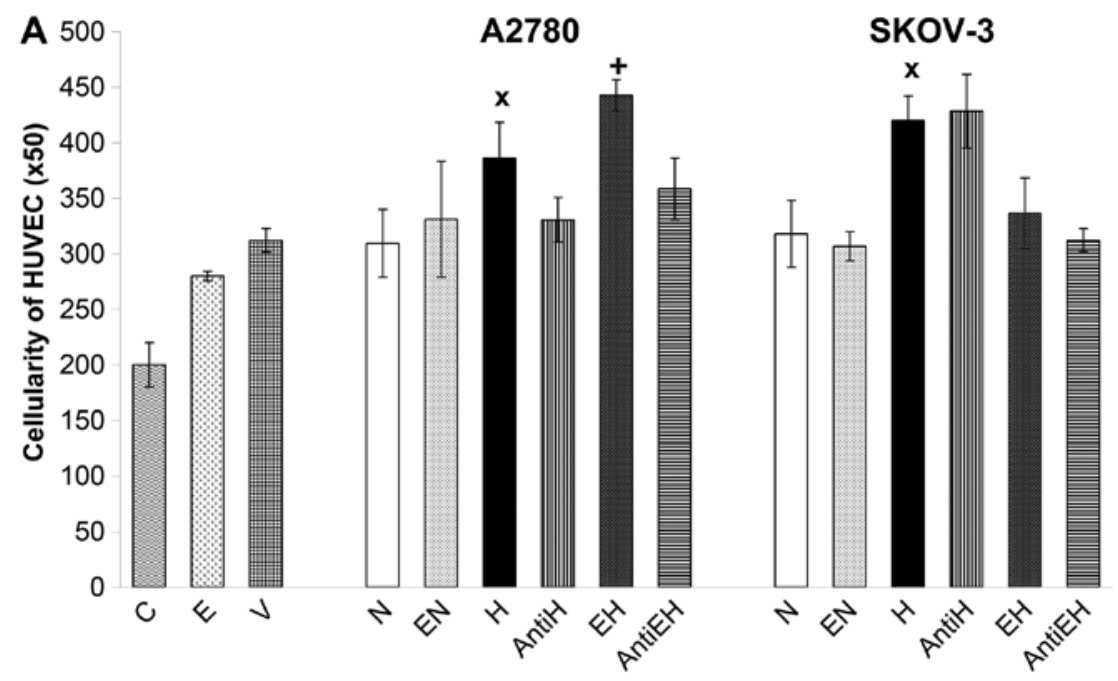

B
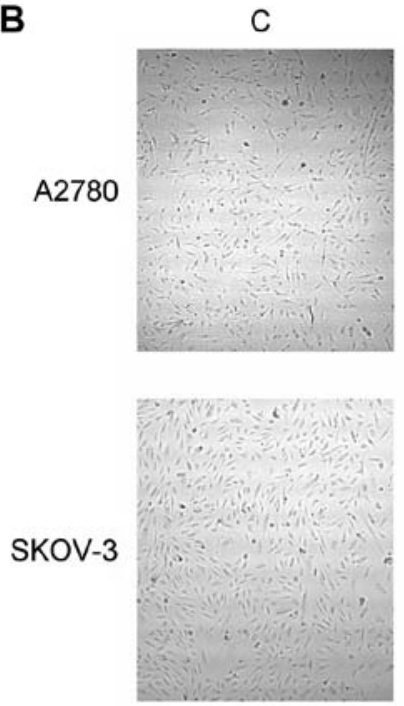
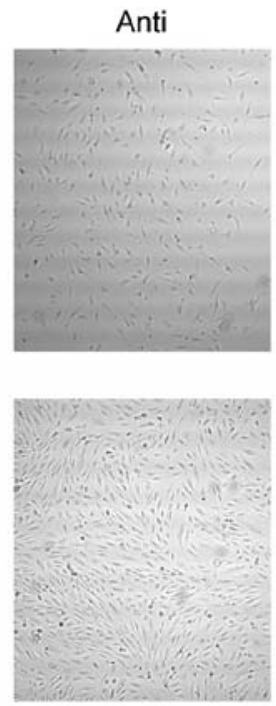
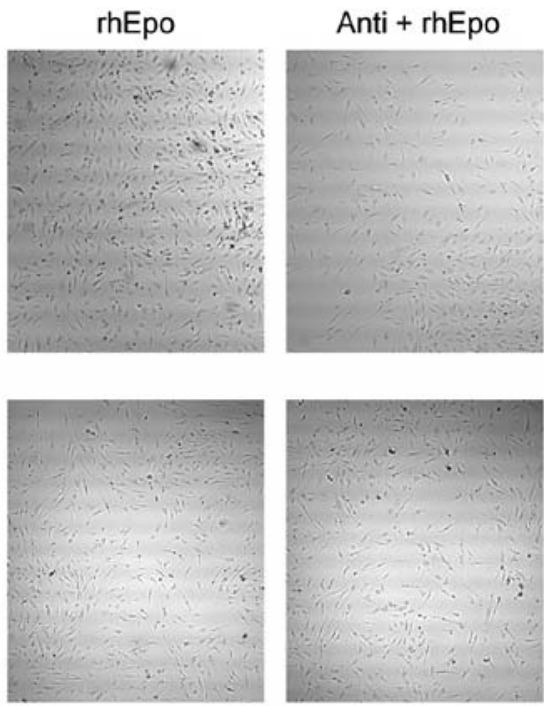

Figure 4. The conditioned media of erythropoietin (Epo)-treated A2780 cells under hypoxia stimulate HUVEC proliferation. (A) The cellularity of HUVECs (C, untreated control) was determined after $48 \mathrm{~h}$ of incubation with $50 \mathrm{U} / \mathrm{ml}$ of recombinant Epo (E), $20 \mathrm{ng} / \mathrm{ml}$ of recombinant vascular endothelial growth factor (VEGF) (V) or conditioned media of A2780 or SKOV-3 cells treated with or without 50 U/ml of recombinant Epo (E) under normoxic (N) or hypoxic (H) conditions. Anti-Epo antibody (Anti, $10 \mu \mathrm{g} / \mathrm{ml}$ ) was used to confirm Epo effect. Data are presented as means \pm SD of three independent experiments. The statistical significance is designated as follows: $\mathrm{H}$ vs. $\mathrm{N}{ }^{x} \mathrm{P}<0.05$ and $\mathrm{EH}$ vs. $\mathrm{H}^{+} \mathrm{P}<0.05$. (B) Representative light microscopy image of $\mathrm{HUVECs}$ after $48 \mathrm{~h}$ incubation with conditioned media of hypoxic A2780 and SKOV-3 cells untreated (C) or treated with Anti-Epo antibody (Anti), 50 U/ml of recombinant Epo (rhEpo) or Anti + rhEpo.

with or without rhEpo (Fig. 4). In this regard, inhibition of HUVECs by hypoxic media of SKOV-3 cells with rhEpo was probably not related to Epo but was due to alternative factors. On the other hand, it appears that endogenous Epo secreted by A2780 cells under hypoxic conditions but also rhEpo added into media of hypoxic A2780 cells could play an important role in the stimulation of endothelial cells represented in our experiment by HUVECs. The effect of such a 'hypoxic' Epo stimulation was also confirmed by increased phosphorylation of STAT-5 protein in HUVECs and by blocking of such signal using anti-Epo antibody (Fig. 5). We also monitored the phosphorylation of Erk1/2 proteins, but there was no marked difference induced by hypoxia or due to rhEpo application; we only observed the difference in Erk1/2 phosphorylation between the conditioned media in general compared with rhVEGF or rhEpo controls (Fig. 5A).
To better understand A2780 conditioned media and its composition in terms of pro- and anti-angiogenic factors, we tested the alterations in the levels of selected cytokines using multi ELISA assay. Based on the results of HUVEC stimulation by conditioned media, we focused more on the content of selected cytokines in conditioned media of A2780 cells treated with rhEpo under hypoxic conditions. It is of note that in this hypoxic media of A2780 cells with rhEpo we found elevated concentrations of IL-4, IL-5, IL-6, IL-8, IL-10, IL-12, IL-13, GM-CSF and IFN- $\gamma$ compared with conditioned media of A2780 hypoxic cells without rhEpo treatment as well as compared with conditioned media of normoxic A2780 cells with or without rhEpo (Fig. 6). The role of rhEpo-induced secretion of the mentioned cytokines in A2780 cells under hypoxic conditions as well as the role of these cytokines in HUVEC stimulation will be studied in our future studies. 

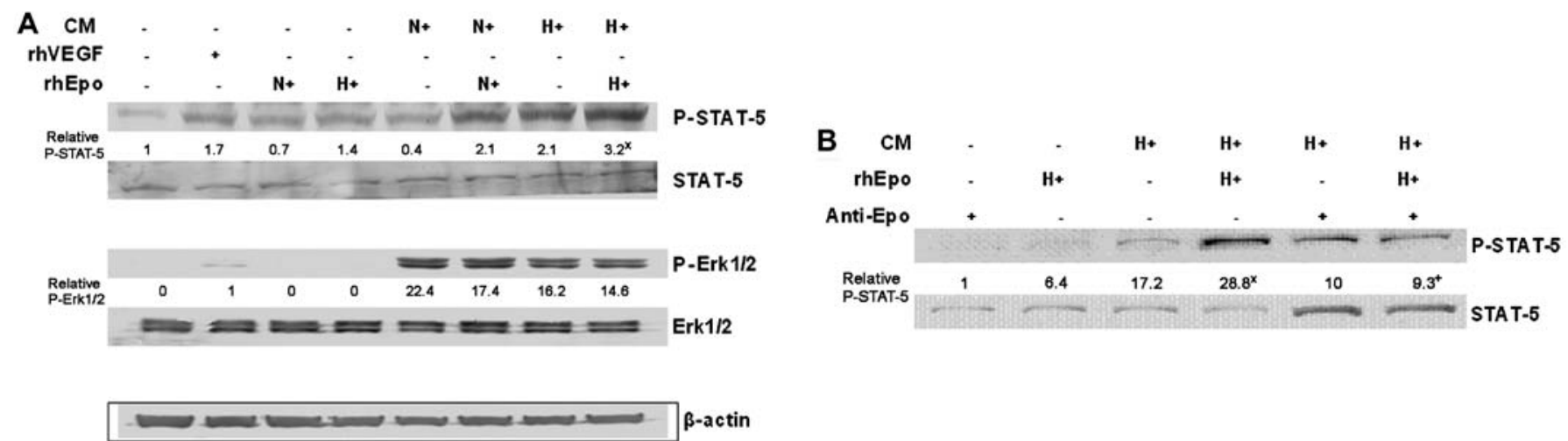

Figure 5. (A) The conditioned media of erythropoietin (Epo)-treated A2780 cells under hypoxia induce STAT-5 signalization in HUVECs. HUVECs were incubated for $30 \mathrm{~min}$ with $20 \mathrm{ng} / \mathrm{ml}$ of recombinant vascular endothelial growth factor (VEGF) (rhVEGF), $50 \mathrm{U} / \mathrm{ml}$ of recombinant Epo (rhEpo) or conditioned media $(\mathrm{CM})$ of A2780 cells treated under normoxic $(\mathrm{N})$ or hypoxic $(\mathrm{H})$ conditions with or without $50 \mathrm{U} / \mathrm{ml}$ of rhEpo. Total cell lysates were prepared. Equal loading was confirmed by detection of $\beta$-actin expression. The relative amounts (densitometric levels) of P-STAT-5 and P-Erk1/2 were normalized to STAT-5 and Erk1/2, respectively. Data are presented as representative image of three western blots and as means of densities taken from three independent experiments. The statistical significance is designated as follows: $\mathrm{H}+$ rhEpo vs. $\mathrm{H}{ }^{\times} \mathrm{P}<0.05$. (B) The Anti-Epo reduces STAT-5 signalization of HUVECs induced by conditioned media of hypoxic A2780 cells with or without Epo. HUVECs were incubated for $30 \mathrm{~min}$ with $10 \mu \mathrm{g} / \mathrm{ml}$ of Anti-Epo antibody (Anti-Epo), 50 U/ml of rhEpo or CM of A2780 cells treated under H conditions with or without $50 \mathrm{U} / \mathrm{ml}$ of rhEpo. Total cell lysates were prepared. Equal loading was confirmed by detection of $\beta$-actin expression. The relative amount (densitometric levels) of P-STAT-5 was normalized to STAT-5. Data are presented as representative image of three western blots and as means of densities taken from three independent experiments. The statistical significance is designated as follows: $\mathrm{H}+\mathrm{rhEpo}$ vs. $\mathrm{H},{ }^{\times} \mathrm{P}<0.05 ; \mathrm{H}+\mathrm{rhEpo}+$ Anti vs. $\mathrm{H}+\mathrm{rhEpo},{ }^{+} \mathrm{P}<0.05$.

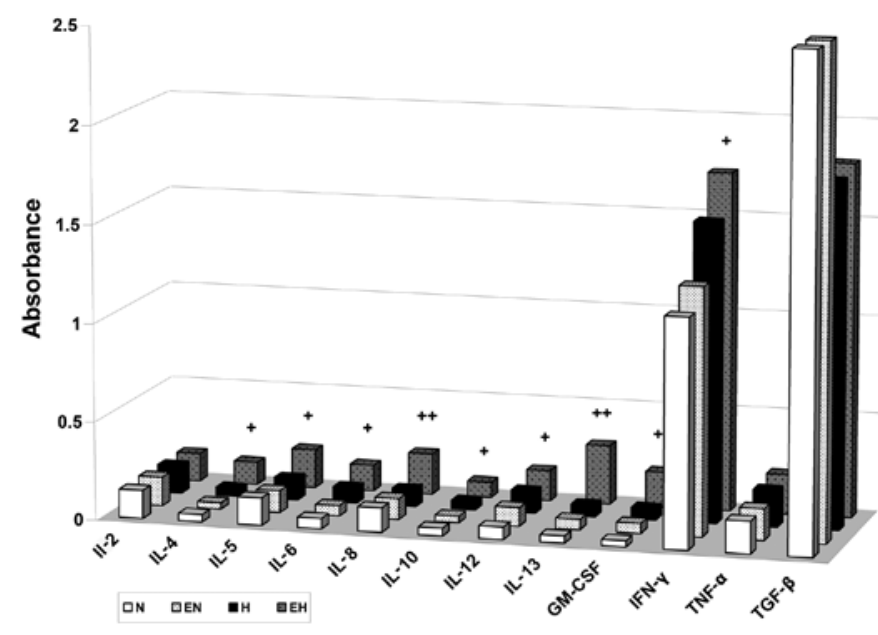

Figure 6. Erythropoietin (Epo) induces secretion of interleukin (IL)-4, IL-5, IL-6, IL-8, IL-10, IL-12, IL-13, GM-CSF and interferon (IFN)- $\gamma$ cytokines in A2780 cells under hypoxic conditions. A2780 cells were treated with or without $50 \mathrm{U} / \mathrm{ml}$ of recombinant Epo $(\mathrm{E})$ under normoxic $(\mathrm{N})$ or hypoxic $(\mathrm{H})$ conditions for $24 \mathrm{~h}$. The levels of IL-2, IL-4, IL-5, IL-6, IL-8, IL-10, IL-12, IL-13, GM-CSF, IFN- $\gamma$, tumor necrosis factor (TNF)- $\alpha$ and transforming growth factor (TGF)- $\beta 1$ in conditioned media are presented as means of the absorbance of three independent experiments. The statistical significance is designated as follows: $\mathrm{EH}$ vs. $\mathrm{H},{ }^{+} \mathrm{P}<0.05$ or ${ }^{++} \mathrm{P}<0.01$.

\section{Discussion}

Epo stimulates cells through its interaction with the EpoR on the cell surface. The EpoR has been identified not only in the hematopoietic cells, but also in a number of non-hematopoietic cells and tissues (30). Despite the fact that several of the tumor cells were confirmed by the presence of the EpoR, the discrepancy in the stimulatory effect of Epo on these cells remains. On the one hand, there are published reports that indicate the proliferative response of cancer cells following rhEpo treatment (31-33), on the other hand, tumor cells, in spite of evidence of EpoR functionality $(4,6)$, did not exhibit a growth Epo response $(4,5,34)$. Although Paragh et al $(5)$ suggested the Epo-independent, EpoR-mediated pathway in the growth of some types of human cancer, additional experiments aimed at typing EpoR are necessary to clarify this contradiction.

There is increasing experimental evidence on the stimulatory effect of Epo on endothelial cell proliferation and/or angiogenesis of tumors. Epo secreted by glioma tumor cells affected glioma vascular endothelial cells via its receptor and promoted angiogenesis in a paracrine manner (20); recently, Epo induced angiogenesis in Matrigel plug assays, and neutralization of Epo secreted by melanoma cells resulted in decreased angiogenesis (21).

Our results provide evidence of the effect of conditioned media of different ovarian adenocarcinoma A2780 and SKOV-3 cells on the proliferation of HUVECs. We hypothesized a stimulatory effect of conditioned media of A2780 and SKOV-3 cells that grew under hypoxic conditions on HUVECs. Our new finding is the fact that pro-stimulatory effect of hypoxic A2780 media, but not SKOV-3, was partly mediated by Epo protein. This was confirmed by increased secretion of Epo by A2780 cells under hypoxia but mainly via the blocking effect of anti-Epo on HUVEC proliferation. Nevertheless, the key drivers of angiogenesis are VEGF molecules (35), at least in A2780 cells Epo appears to also be an important stimulus. An interesting fact remains that despite increased A2780 cell secretion of Epo molecules, neither HIF-1 $\alpha$ or Epo gene overexpression in these cells was observed. This result was probably due to increased stabilization of Epo protein. On the other hand, SKOV-3 cells with eight times higher mRNA levels for HIF-1 $\alpha$ than A2780 cells, respond to hypoxia by increased VEGF expression associated with enhanced secretion of VEGF into the media. Increase of VEGF secretion was observed in SKOV-3 cells also after incubation with rhEPO in normoxic conditions without altering VEGF gene expression. Our previous study showed that SKOV-3 compared to 
A2780 cells constitutive expression of Akt and basal level of phosphorylated Ser473 (activated by overexpression of HER2), which was even enhanced after $24 \mathrm{~h}$ incubation of SKOV-3 cells with rhEpo in normoxic conditions (36). Taking into account that activation of the PI3K/Akt/mTOR pathway can increase (37) and considering our previous results (36) rhEpo now increased secretion of VEGF in SKOV-3 cells under normoxia probably by activation of the Akt pathway followed by increased stabilization of VEGF mRNA or higher translation of VEGF protein.

The mechanism of tumor growth in the context of Epo is not completely clarified, and it remains unclear whether there is a direct effect of Epo in tumor cells as opposed to exogenous effect on angiogenesis (26). We previously demonstrated that each of four human ovarian cancer cell lines, A2780, CaOV, SKOV-3 and OVCAR-3, expresses the EpoR but none of the cell lines exhibited a growth response in culture to exogenous Epo in normoxic conditions (38). Presently, rhEpo (50 U/ml) did not affect the proliferation of hypoxic A2780 and SKOV-3 cells measured by incorporation of BrdU (data not shown). rhEpo did not even affect the expression of selected genes associated with tumor angiogenesis. If there were any changes in the expression of HIF-1 $\alpha$, Epo and VEGF, they were induced by lower oxygen pressure not by exogenous Epo. This finding is in contrast with results of Hale et al (39) where Epo significantly reduced hypoxia-induced VEGF expression in SKOV-3 and MCF-7 cells. However, the authors did not use anti-Epo or soluble EpoR to confirm specificity of Epo effect. Our result with stimulatory effects of conditioned media of hypoxic A2780 cells treated with rhEpo on HUVECs is also in contrast to the findings of Hale et al (39). This effect was, however, the specific effect of Epo due to its blocking via anti-Epo antibody.

Epo signaling as a mitogen of endothelial cells was conducted via tyrosine phosphorylation of proteins including phosphorylation of transcription factor STAT-5, which is similar to that occurring in erythroid cells (40). Moreover, experiments performed in cultured vascular cells demonstrated that Epo strongly induced phosphorylation of STAT-5 in HUVECs, but only very weakly in smooth muscle cells (41). We observed STAT-5 signalization in HUVECs after their 30-min incubation with either conditioned media of hypoxic A2780 cells with or without addition of rhEpo or conditioned media of normoxic A2780 cells with rhEpo. Notably, we found the association between increased phosphorylation of STAT-5 and HUVEC stimulation only in hypoxic media of A2780 cells with or without rhEpo, not in normoxic media with rhEpo. On the other hand, anti-Epo antibody significantly reduced A2780 hypoxic media with or without rhEpo induced STAT-5 phosphorylation as well as proliferation of HUVECs. The stimulative effect of secreted as well as rhEpo on HUVECs could be explained by different levels of pro- and anti-angiogenic cytokines secreted by A2780 cells under the hypoxic conditions compared with normoxic ones.

Cancer cells secrete several angiogenic factors, such as VEGF, bFGF, PDGF, IL-6 and IL-8 (42-45) and cytokines, such as MCP-1, G-CSF, M-CSF, TNF $\alpha$, IL- $1 \alpha$ and IL-1 $\beta$ (46-49). These cytokines could bind to their receptors expressed by endothelial and hematopoietic/lymphoid cells and induce production of additional types of cytokines (50). In this regard, IL- 6 produced by human ovarian epithelial cells (43) can stimulate inflammatory cytokine production, tumor angiogenesis and the tumor macrophage infiltrate in ovarian cancer (51). On the other hand, IL-10 had suppressive effects on angiogenesis, tumor growth, and peritoneal dissemination of VEGF-producing ovarian cancer cells (52). IL-4 as well as IL-13 inhibited the migration of cultured bovine or human microvascular cells, showing unusual dose-response curves that were sharply stimulatory at a concentration of $0.01 \mathrm{ng} / \mathrm{ml}$ but inhibitory over a wide range of higher concentrations (53). Similarly, IL-12, a cytokine with both immunostimulatory and anti-angiogenic effects, suppressed both tumor-associated angiogenesis and growth of canine hemangiosarcoma in vivo (54). The treatment of A2780 cells with rhEpo under hypoxic conditions led to increased secretion of IL-4, IL-5, IL-6, IL-8, IL-10, IL-12, IL-13, GM-CSF and IFN- $\gamma$ cytokines. The role of individual pro- and anti-angiogenic cytokines in HUVEC stimulation will be examined in future studies. It is critical to determine which cytokines are secreted by HUVECs in response to conditioned media with or without Epo. The final effect of Epo on HUVECs will probably depend on the balance between pro- and anti-angiogenic cytokines in an environment of HUVECs.

Our results revealed that conditioned media of rhEpo-treated A2780 cells under hypoxic conditions induced significant STAT-5 phosphorylation as well as proliferation of HUVECs. Furthermore, rhEpo increased secretion of IL-4, IL-5, IL-6, IL-8, IL-10, IL-12, IL-13, GM-CSF and IFN- $\gamma$ by A2780 cells in hypoxic conditions.

\section{Acknowledgements}

This study was supported by the Slovak Research and Development Agency under contract no. VVCE-0001-07 and LPP-0062-09 and the Scientific Grant Agency of the Ministry of Education of the Slovak Republic under contract nos. VEGA 1/0296/09, VEGA 1/0733/12 and the NEXO (Network of Excellence in Oncology) under contract no. ITMS 26220120024.

\section{References}

1. Sytkowski AJ: Erythropoietin: Blood, Brain and Beyond. Wiley-VCH, Weinheim, 2004.

2. Miller CP, Lowe KA, Valliant-Saunders K, et al: Evaluating erythropoietin-associated tumor progression using archival tissues from a phase III clinical trial. Stem Cells 27: 2353-2361, 2009.

3. Swift S, Ellison AR, Kassner P, et al: Absence of functional EpoR expression in human tumor cell lines. Blood 115: 4254-4263, 2010.

4. Jeong JY, Feldman L, Solar P, Szenajch J and Sytkowski AJ: Characterization of erythropoietin receptor and erythropoietin expression and function in human ovarian cancer cells. Int $\mathbf{J}$ Cancer 122: 274-280, 2008.

5. Paragh G, Kumar SM, Rakosy Z, Choi SC, Xu X and Acs G: RNA interference-mediated inhibition of erythropoietin receptor expression suppresses tumor growth and invasiveness in A2780 human ovarian carcinoma cells. Am J Pathol 174: 1504-1514, 2009.

6. Solar P, Hrckova G, Varinska L, et al: Location and the functionality of erythropoietin receptor(s) in A2780 cells. Oncol Rep 28: 141-146, 2012.

7. Szenajch J, Wcislo G, Jeong JY, Szczylik C and Feldman L: The role of erythropoietin and its receptor in growth, survival and therapeutic response of human tumor cells From clinic to bench - a critical review. Biochim Biophys Acta 1806: 82-95, 2010. 
8. Anagnostou A, Lee ES, Kessimian N, Levinson R and Steiner M Erythropoietin has a mitogenic and positive chemotactic effect on endothelial cells. Proc Natl Acad Sci USA 87: 5978-5982, 1990.

9. Carlini RG, Dusso AS, Obialo CI, Alvarez UM and Rothstein M: Recombinant human erythropoietin (rHuEPO) increases endothelin-1 release by endothelial cells. Kidney Int 43: 1010-1014, 1993.

10. Carlini RG, Reyes AA and Rothstein M: Recombinant human erythropoietin stimulates angiogenesis in vitro. Kidney Int 47 740-745, 1995.

11. Anagnostou A, Liu Z, Steiner M, et al: Erythropoietin receptor mRNA expression in human endothelial cells. Proc Natl Acad Sci USA 91: 3974-3978, 1994.

12. Yamaji R, Okada T, Moriya M, et al: Brain capillary endothelial cells express two forms of erythropoietin receptor mRNA. Eur J Biochem 239: 494-500, 1996.

13. Yasuda Y, Masuda S, Chikuma M, Inoue K, Nagao M and Sasaki R: Estrogen-dependent production of erythropoietin in uterus and its implication in uterine angiogenesis. J Biol Chem 273: 25381-25387, 1998

14. Ribatti D, Presta M, Vacca A, et al: Human erythropoietin induces a pro-angiogenic phenotype in cultured endothelial cells and stimulates neovascularization in vivo. Blood 93: 2627-2636, 1999.

15. Haroon ZA, Amin K, Jiang X and Arcasoy MO: A novel role for erythropoietin during fibrin-induced wound-healing response. Am J Pathol 163: 993-1000, 2003.

16. Kertesz N, Wu J, Chen TH, Sucov HM and Wu H: The role of erythropoietin in regulating angiogenesis. Dev Biol 276: 101-110, 2004.

17. Yasuda Y, Fujita Y, Musha T, et al: Expression of erythropoietin in human female reproductive organs. Ital J Anat Embryol 106 (Suppl 2): S215-S222, 2001.

18. Yasuda Y, Fujita Y, Masuda S, et al: Erythropoietin is involved in growth and angiogenesis in malignant tumours of female reproductive organs. Carcinogenesis 23: 1797-1805, 2002.

19. Nakamatsu K, Nishimura Y, Suzuki M, Kanamori S, Maenishi O and Yasuda Y: Erythropoietin/erythropoietin-receptor system as an angiogenic factor in chemically induced murine hepatic tumors. Int J Clin Oncol 9: 184-188, 2004.

20. Nico B, Annese T, Guidolin D, Finato N, Crivellato E and Ribatti D: Epo is involved in angiogenesis in human glioma. J Neurooncol 102: 51-58, 2011.

21. Kumar SM, Zhang G, Bastian BC, et al: Erythropoietin receptor contributes to melanoma cell survival in vivo. Oncogene 31: $1649-1660,2012$

22. Okazaki T, Ebihara S, Asada M, Yamanda S, Niu K and Arai $\mathrm{H}$ : Erythropoietin promotes the growth of tumors lacking its receptor and decreases survival of tumor-bearing mice by enhancing angiogenesis. Neoplasia 10: 932-939, 2008.

23. Ribatti D, Marzullo A, Gentile A, et al: Erythropoietin/erythropoietin-receptor system is involved in angiogenesis in human hepatocellular carcinoma. Histopathology 50: 591-596, 2007.

24. Ribatti D, Nico B, Perra MT, et al: Erythropoietin is involved in angiogenesis in human primary melanoma. Int J Exp Pathol 91: 495-499, 2010

25. Li HG, Li JS, Chen WL, Wang L, Wu DH and Lin ZY: Prognostic significance of erythropoietin and erythropoietin receptor in tongue squamous cell carcinoma. Br J Oral Maxillofac Surg 47: 470-475, 2009.

26. Ribatti D: Erythropoietin and tumor angiogenesis. Stem Cells Dev 19: 1-4, 2010

27. Wang L, Li HG, Xia ZS, Wen JM and Lv J: Prognostic significance of erythropoietin and erythropoietin receptor in gastric adenocarcinoma. World J Gastroenterol 17: 3933-3940, 2011.

28. Van Hinsbergh VW, Sprengers ED and Kooistra T: Effect of thrombin on the production of plasminogen activators and PA inhibitor-1 by human foreskin microvascular endothelial cells. Thromb Haemost 57: 148-153, 1987.

29. Defilippi P, van Hinsbergh V, Bertolotto A, Rossino P, Silengo L and Tarone G: Differential distribution and modulation of expression of alpha $1 /$ beta 1 integrin on human endothelial cells. J Cell Biol 114: 855-863, 1991.

30. Arcasoy MO, Jiang X and Haroon ZA: Expression of erythropoietin receptor splice variants in human cancer. Biochem Biophys Res Commun 307: 999-1007, 2003.
31. Westenfelder C and Baranowski RL: Erythropoietin stimulates proliferation of human renal carcinoma cells. Kidney Int 58: 647-657, 2000

32. Lai SY, Childs EE, Xi S, et al: Erythropoietin-mediated activation of JAK-STAT signaling contributes to cellular invasion in head and neck squamous cell carcinoma. Oncogene 24: 4442-4449, 2005.

33. Feldman L, Wang Y, Rhim JS, Bhattacharya N, Loda M and Sytkowski AJ: Erythropoietin stimulates growth and STAT5 phosphorylation in human prostate epithelial and prostate cancer cells. Prostate 66: 135-145, 2006.

34. Selzer E, Wacheck V, Kodym R, et al: Erythropoietin receptor expression in human melanoma cells. Melanoma Res 10: 421-426, 2000.

35. Ferrara N: VEGF and the quest for tumour angiogenesis factors. Nat Rev Cancer 2: 795-803, 2002.

36. Solar P, Koval J, Mikes J, et al: Erythropoietin inhibits apoptosis induced by photodynamic therapy in ovarian cancer cells. Mol Cancer Ther 7: 2263-2271, 2008.

37. Karar J and Maity A: PI3K/AKT/mTOR pathway in angiogenesis. Front Mol Neurosci 4: 51, 2011.

38. Solar P, Feldman L, Jeong JY, Busingye JR and Sytkowski AJ: Erythropoietin treatment of human ovarian cancer cells results in enhanced signaling and a paclitaxel-resistant phenotype. Int J Cancer 122: 281-288, 2008.

39. Hale SA, Wong C and Lounsbury KM: Erythropoietin disrupts hypoxia-inducible factor signaling in ovarian cancer cells. Gynecol Oncol 100: 14-19, 2006.

40. Haller H, Christel C, Dannenberg L, Thiele P, Lindschau C and Luft FC: Signal transduction of erythropoietin in endothelial cells. Kidney Int 50: 481-488, 1996.

41. Janmaat ML, Heerkens JL, de Bruin AM, Klous A, de Waard V and de Vries CJ: Erythropoietin accelerates smooth muscle cell-rich vascular lesion formation in mice through endothelial cell activation involving enhanced PDGF-BB release. Blood 115: 1453-1460, 2010.

42. Sonoda T, Kobayashi H, Kaku T, Hirakawa T and Nakano H: Expression of angiogenesis factors in monolayer culture, multicellular spheroid and in vivo transplanted tumor by human ovarian cancer cell lines. Cancer Lett 196: 229-237, 2003.

43. Lidor YJ, Xu FJ, Martinez-Maza O, et al: Constitutive production of macrophage colony-stimulating factor and interleukin-6 by human ovarian surface epithelial cells. Exp Cell Res 207: 332-339, 1993.

44. Di Blasio AM, Carniti C, Vigano P and Vignali M: Basic fibroblast growth factor and ovarian cancer. J Steroid Biochem Mol Biol 53: 375-379, 1995 .

45. Versnel MA, Haarbrink M, Langerak AW, et al: Human ovarian tumors of epithelial origin express PDGF in vitro and in vivo. Cancer Genet Cytogenet 73: 60-64, 1994.

46. Negus RP, Stamp GW, Relf MG, et al: The detection and localization of monocyte chemoattractant protein-1 (MCP-1) in human ovarian cancer. J Clin Invest 95: 2391-2396, 1995.

47. Savarese TM, Mitchell K, McQuain C, et al: Coexpression of granulocyte colony stimulating factor and its receptor in primary ovarian carcinomas. Cancer Lett 162: 105-115, 2001.

48. Glezerman M, Mazot M, Maymon E, et al: Tumor necrosis factoralpha and interleukin- 6 are differently expressed by fresh human cancerous ovarian tissue and primary cell lines. Eur Cytokine Netw 9: 171-179, 1998

49. Gorelik E, Landsittel DP, Marrangoni AM, et al: Multiplexed immunobead-based cytokine profiling for early detection of ovarian cancer. Cancer Epidemiol Biomarkers Prev 14: 981-987, 2005.

50. Muller L and Pawelec G: Cytokines and antitumor immunity. Technol Cancer Res Treat 2: 183-194, 2003.

51. Coward J, Kulbe H, Chakravarty P, et al: Interleukin-6 as a therapeutic target in human ovarian cancer. Clin Cancer Res 17: 6083-6096, 2011

52. Kohno T, Mizukami H, Suzuki M, et al: Interleukin-10-mediated inhibition of angiogenesis and tumor growth in mice bearing VEGF-producing ovarian cancer. Cancer Res 63: 5091-5094, 2003.

53. Volpert OV, Fong T, Koch AE, et al: Inhibition of angiogenesis by interleukin 4. J Exp Med 188: 1039-1046, 1998.

54. Akhtar N, Padilla ML, Dickerson EB, et al: Interleukin-12 inhibits tumor growth in a novel angiogenesis canine hemangiosarcoma xenograft model. Neoplasia 6: 106-116, 2004. 